\title{
Infant Educators' Use of Pedagogical Questioning: Relationships with the Context of Interaction and Educators' Qualifications
}

Sheila Degotardi, Jane Torr and Feifei Han

Department of Educational Studies, Macquarie University, Sydney, Australia

\begin{abstract}
Research Findings: This study investigated the prevalence of pedagogical questions posed by 27 early childhood educators as they interacted with infants in each of two different contexts: book-focused interactions and educator-mediated play. The pedagogical questions expressed by educators to infants during ten-minute naturally-occurring interactions were coded as confirm (yes/no), specify (what, who, where, when) or explain (why, how) questions on the basis that these types of questions present infants with different opportunities to use their developing communication skills to provide information to others. We then sought to determine associations between question use, activity context and educators' qualification levels. Results revealed that explain questions were used very rarely, while confirm and specify questions were more frequent, comprising $7.60 \%$ and $8.32 \%$ respectively of messages that were expressed by educators to the infants in their care. A 2 (activity context) $\mathrm{x} 2$ (qualification level) mixed factorial MANOVA, supplemented with post-hoc qualitative analyses, demonstrated that, in specific activity contexts, degree qualified early childhood teachers used pedagogical questioning in ways which differed from their less-qualified counterparts. Practice or policy: The findings provide much needed data on how educator questioning is used with children under two, how questioning affords context-specific language learning opportunities for infants in ECEC centres, and how educator qualifications may be implicated in these opportunities.
\end{abstract}

\section{Keywords}


Infants; educators; interactions; questioning; reading; play

It is widely accepted that a language rich environment in early childhood is vital for children's current and future language development (Hoff, 2006; Zauch, Thul, Mahoney, \& Stapel-Wax, 2016). Yet there is still much to learn about the language environment experienced by infants in non-parental group care settings, particularly in relation to the extent to which educators' talk may support the language development of children under the age of two (hereafter referred to as infants). This study investigates one type of educator talk, questioning, and the manner in which it is deployed across two different learning contexts in early childhood education and care (ECEC) centres; book-focused interactions and educator-mediated play. We present quantitative and qualitative data to determine whether educators' early childhood qualification levels relate to the patterns of questioning that these educators habitually employ in their interactions with infants. Our findings have implications for understanding how educator questioning is used pedagogically with infants in different activity contexts, as well as how educator qualification levels are related to their use of questioning for infants' language development and learning more generally.

The importance of educators' use of questioning as a pedagogical strategy is strongly entrenched in early childhood research and professional literature. Siraj-Blatchford and Manni (2008) describe how questioning has long been upheld as a strategy that encourages children's active participation in interactions, which in turn can extend learning. Questioning, they explain, prompts children to share their thinking with others, and thus opens up ideas for reflection and negotiation. While this strategy has attracted strong early childhood research interest, much of this research has focused on children aged from three to five years, who already have some facility to use language as a vehicle for language development and learning (e.g., Allerton, 1993; Bateman, 2013; Chappell, Craft, Burnard, \& Cremin, 2008; 
Massey, Pence, Justice, \& Bowles, 2008; McGee \& Richgels, 2003; Siraj-Blatchford \& Manni, 2008; Snow \& Uccelli, 2009; Wittmer \& Honig, 1991). What is unclear is the extent to which educators use this strategy with infants, who are in the early stages of learning and using their first language(s). As increasing numbers of infants attend ECEC centres worldwide, an analysis of infant educators' use of questioning will therefore extend current understandings of the pedagogical strategies used with these very young children.

\section{Defining Pedagogical Questioning}

In this study, the term pedagogical questioning is used to refer to educators' questions which have an explicitly educational intention, as they are concerned with the construction of knowledge and linguistic representation of experience (e.g., What's this?; Who's that?; What does the ducky say?). These questions contrast with those which, while grammatically interrogative in form, nevertheless serve as an indirect expression of a command (e.g., Could you sit down please? while placing the infant on a chair), an offer (e.g., Some apple for you? while placing apple on the child's plate) and formulaic expressions (e.g., Pardon?) (Hasan, 1996; Hu, Torr, Degotardi, \& Han, 2017). When educators use questioning as a pedagogical strategy, they are simultaneously supporting children's language development, and their ability to learn how to use language as a vehicle for learning (Davis \& Torr, 2015).

\section{Relationship between Questioning and Infants' Language Opportunities}

The significance of educators' questioning is supported by several studies that have identified it as one of the characteristics of infant-directed speech associated with infants' language opportunities in ECEC centre contexts. Girolametto and Weitzman (2002) studied the language supporting efforts of 26 toddler and preschool educators. The authors found that a measure of 'interaction promoting' strategies, comprising a composite score of educators' question use, their encouragement of turn-taking, and ability to scan the children involved in 
order to ensure that all are included in the interaction, was positively correlated with measures of toddlers' and preschoolers' verbal production. Their findings extend those of studies exclusively with preschool-aged children (Cabell, Justice, McGinty, DeCoster, \& Forson, 2015; Justice, Jiang, \& Strasser, 2018) to conclude that educators' questioning plays a role in encouraging younger children to participate in conversational exchanges.

A related study, however, introduces complexity to the pedagogical potential of the use of questions. Girolametto, Weitzman, van Lieshout, and Dawna (2000) investigated 20 early childhood educators' directive talk when interacting with small groups of children during a book reading and play-dough activity. Of particular relevance to the present study was their examination of educators' use of questioning for different purposes. They found that educators used 'test' questions (which asked children to provide a known, correct answer) and directive 'yes/no' questions in order to control children's responses. In contrast, 'wh' (information seeking) and clarification questions were used in the context of establishing conversational topics and eliciting conversational responses. Educators' use of these information-seeking, conversational questions, but not the response-controlling questions, was significantly correlated with child talkativeness, lexical diversity, and complexity, leading the researchers to conclude that question types have different implications for young children's participation in language and learning interactions. Further complexity is highlighted in an earlier study by Cicognani and Zani (1992), who included explanationseeking questions in their comparison of a suite of language-promoting strategies used by educators of one-year-old and three-year-old children. They found that educators used explanation-seeking questions very rarely with the younger age group. These findings, together with those of Giralometto and colleagues above, suggest that a nuanced analysis of educator questions is needed in order to understand the age-specific language and learning potential that they offer to infants. 


\section{Semantic Patterns in Adults' Use of Child-directed Questioning}

To contribute to a more nuanced analysis of infant educators' use of pedagogical questions, this study focuses on the underlying patterns of meaning realised in educators' questioning. Drawing on Hasan's $(1989,1991)$ semantic networks, underpinned by systemic functional linguistic theory (Halliday, 1994), the current study focuses on educators' pedagogical questioning in order to request information from the interactant (e.g., Where is the snail?; What's that?; Who's there?).

Hasan makes a semantic distinction between three types of pedagogical questions. A confirm question, realised grammatically as a polar interrogative, seeks either a confirmation (yes) or refutation (no) of a particular proposition (e.g., Is that a red one?). A specify question, realised grammatically as a 'wh' interrogative (who, when, where, what) seeks the name of a person, place, time or entity (e.g., Where is she going?; What's that?). An explain question, realised grammatically as a 'wh' interrogative (why, how) seeks a reason or explanation (e.g., Why did she get wet?; How did you make your castle?). A full account of the semantic network representing information exchange can be found in Hasan (1996).

Hasan proposes that, when considered within the context of the surrounding dialogue, the semantic choices realised by different questions play an important role in the learning potential of young children's language interactions. Confirm questions may enable the adult to 'tune in'; to seek explicit confirmation that they have correctly understood the child's experiences, ideas and intentions, and to verbally represent them. Specify and explain questions may provide the child with opportunities to represent their experiences, and verbally display their knowledge, understanding and point of view. This suggests that individual variation in educators' use of questioning will generate different language and learning opportunities for children. 
Hasan's $(1991,1996)$ semantic distinctions therefore provide a valuable analytical framework with which to investigate the frequency, qualitative characteristics and learning potential of educators' use of pedagogical questions. As Hasan's research was derived from home-based studies of mothers with preschool-aged children, what is currently unknown is the extent to which the distinctions included in her semantic network are used by infant educators in ECEC settings. Unlike preschoolers, infants are in the early stages of acquiring and using language to communicate with others, and are unlikely to be able to provide verbally explicit responses to educators' questions (Cicognani \& Zani, 1992). While questioning may be widely regarded as a valuable pedagogical strategy with older children (Cabell et al., 2015; Justice et al., 2018; Siraj-Blatchford \& Manni, 2008), findings from studies with older children may not be generalizable to interactions with very young children. Therefore, our first research aim is to employ Hasan's framework to examine the extent to which infant educators address the three types of pedagogical questions (confirm, specify, and explain) to infants in ECEC centres. 


\section{Explaining Variation in Educators' Use of Questioning}

Our second research aim is to describe and explain variation in educators' infantaddressed questioning. One line of empirical enquiry will investigate educator qualifications on the basis that many studies demonstrate that more highly-qualified infant educators tend to exhibit a higher quality of learning-enhancing interaction than their lower-qualified colleagues (Degotardi, 2010; Goelman et al., 2006; Manlove, Vazquez, \& Vernon-Feagans, 2008; National Institute of Child Health and Human Development Early Child Care Research Network, 2002). Recent work has also detected significant differences in the qualities of language-enhancing strategies of higher and lower qualified educators (Degotardi, Torr, \& Nguyen, 2016; Hu et al., 2017), suggesting that specialised early childhood knowledge has a flow on effect to the quality of the language features of educators' interactions with children. However, whether or not qualification levels are related specifically to infant educators' use of questioning is currently unknown.

A second possible explanation for variation lies in the language-learning opportunities associated with different activity contexts. The context of the educator-child interaction has also been found to relate to the frequency and type of educators' use of questions. In an early study, O'Brien and Bi (1995) found that educators varied in their use of 'yes/no' and 'wh' questions across three different play situations: play with dolls, play with blocks and large motor play. During doll play, educators asked more 'yes/no' questions compared with the other two situations, and more 'wh' questions than in large motor play. Girolametto and Weitzman (2002) found that educators' use of questions was significantly higher in the playdough activity than in the book reading context. More specific context-related differences were reported by Girolametto et al. (2000), who found the educators used significantly more 'test' questions, defined as those that seek an already known answer, and 'yes/no' questions, 
and significantly fewer 'wh' clarification and conversational 'yes/no' questions during book reading than during the playdough activity. Together, these findings suggest that specific activity contexts afford different opportunities for educators to ask questions, and that specific question types may also be privileged to a greater or lesser extent depending on the nature of the activity taking place.

Our second research aim is therefore to examine whether the context of the interaction and educators' qualification levels are related to their use of pedagogical questioning. We investigate whether educators with different levels of qualifications have different patterns of questioning use across different activity contexts, and whether qualitative differences exist alongside quantitative differences.

\section{The Current Study}

In sum, little is currently known about whether, and if so, how and to what extent educators use pedagogical questioning in their infant-addressed talk. Using Hasan's $(1991,1996)$ semantic networks as an analytical framework, the current study describes and explains variations in ECEC educators' use of pedagogical questioning in different activity contexts by addressing the following questions:

1. How frequently do educators use confirm, specify and explain pedagogical questions overall and in different activity contexts when interacting with infants?

2. To what extent do activity contexts and educators' early childhood qualification levels explain variations in educators' pedagogical questioning?

\section{Method}

\section{Recruitment and Data Collection}

The educators in this study were drawn from a federally funded research project (grant reference $\mathrm{XXX}$ ), which investigated the language environment experienced by infants aged 
up to age two attending ECEC programs in [country]. The recruitment process commenced with an initial invitation email to ECEC centres within and around the XXX metropolitan area. These centres were largely drawn from several not-for-profit and private ECEC providers who consented to allow their centres to participate. Further centres were invited from a database used for early childhood practicum placement at XXX university. In total 89 ECEC centres were approached and 59 agreed to participate. Due to scheduling and technical difficulties, insufficient data was collected from three centres. The resulting 56 participating centres comprised 34 not-for-profit services, 18 privately owned services, and four workbased services. Ethics approval was obtained from [name of university] and all requirements relating to informed consent for participating educators and attending infants, as well as protocols relating to the sensitive, respectful collection of data, were adhered to.

One focus educator from each infant room in the participating centre was recruited to participate. Data were collected across three visits by research assistants (RAs), all of whom had prior experience working with infants in ECEC settings. During the first visit, the RAs familiarised themselves with the room layout and daily schedule of room, and recorded the focus educator's ECEC qualifications. During the second and third visits, the RAs videorecorded the focus educator for 1.5 hours using a small hand-held video-recorder. The focus educator wore a blue-tooth microphone so that high quality audio-recordings of their interactions with infants could be captured. The videos filmed the naturally occurring behaviours of the focus educators, who were involved in a range of activities, including indoor and outdoor play, art activities, book-focused interactions, meals and personal care (e.g., nappy change and handwashing). 


\section{Data and Participant Selection for the Present Study}

The present study examined educators' questions during book-focused interaction and educator-mediated play, both of which are common activities in infant early childhood rooms that offer ample opportunities for educator-infant interaction. A book-focused interaction was selected due to the well-established role that book reading plays in children's language development (Bus, van IJzendoorn, \& Pellegrini, 1995). Book-focused interactions provide opportunities for infants and adults to interact around a shared focus and for adults to provide stimulating and varied language input (Fletcher \& Reese, 2005; Gilkerson, Richards, \& Topping, 2015). Educator-mediated play was chosen because it is largely child-directed, yet the active involvement from the educator provides opportunities for the provision of responsive interactions as the educator guides the play and scaffolds infants' learning (Durden \& Dangel, 2008; Girolametto \& Weitzman, 2002; O’Brien \& Bi, 1995).

The following criteria were used to select data. First, the focus educator had to be observed actively attending to one or a small group of children during both a book-focused interaction and an educator-mediated play experience. Book-focused interaction was defined as an activity occurring when the educator and infant/s were jointly attending to the same picture book which had been selected by either infant/s or the educator. Educator-mediated play was referred to as an activity occurring when the educator was actively engaging with infant/s as they played (e.g., with blocks, sand or playdough). To be included for the analysis, each activity had to last for at least 10 minutes. The three hours of each focus educators' video-recording was watched and the first 10-minute segments of book-focused interaction and educator-mediated play were kept as the data.

A comprehensive screening of the 56 focus educators' video-recording revealed that 25 educators did not engage in a book-focused interaction, and of the remaining 31 educators, the 
engagement of four educators' mediated play lasted less than 10 minutes. As a result, 27 educators met our selection criteria ${ }^{1}$. Among them, eight educators had a Bachelor degree in ECEC (degree qualified), and 19 educators had either a Diploma or Certificate vocational qualification in ECEC (non-degree qualified). All the educators were female and all spoke English when interacting with the infants.

\section{Measures}

The two 10-minute segments of each educator's talk were transcribed verbatim. The transcriptions were divided into 'messages' using Hasan's (1991) definition - 'the smallest semantic unit that is capable of entering into the structure of a text' (p. 81). To be included for the analysis, the messages had to be addressed to infant/s, hereby referred to as 'infantdirected messages'. Messages addressed to other adults or self-talk were excluded from the analysis. Further, in the book-focused segment, any text that was a direct reading of the book was excluded. In total, the 27 book-focused and 27 mediated-play segments comprised 11,062 infant-directed messages.

\section{Coding.}

Each infant-directed message was analysed to determine whether or not it was a pedagogical question (as defined above). Each pedagogical question was then coded as one of the following:

Confirm (yes/no) questions ask the respondent to confirm or refute the experiential content of the question (e.g., Is it a snake?; Does that one [train carriage] stick as well?; Are you being a train?; Does it feel nice on your teeth?).

\footnotetext{
${ }^{1}$ A comparison using $t$-tests on the ages and qualification levels between those who met the selection criteria and those excluded showed no significant differences (ages: $t=0.25, p=.80$; and qualification: $t=0.43, p=$. 43).
} 
Specify questions (what, who, whose, when and where) ask the respondent to specify the name of an entity, person, time, place, or action (e.g., What's in there?; Who is it?; Where's Woof?; What's Astrid doing?).

Explain questions (how, why) ask the respondent to provide an explanation, reason or justification (e.g., Why did Scruffy run away?; How did the little mouse get inside?).

As the number of infant-directed messages varied widely between educators across the two activity contexts (book-focused interaction: range $104-383, M=214.67, S D=61.29$; and educator-mediated play: range $94-308, M=195.04, S D=62.55$ ), we used the proportions of the three types of pedagogical questions for the statistical analysis in order to control for this variation. The proportions were calculated by dividing the total number of each type of pedagogical question by the total number of infant-directed messages in each activity context for each focus educator.

\section{Inter-coder reliability.}

To ensure the reliable coding of the data, a second coder independently coded six randomly selected transcripts for each activity context (accounting for approximately $20 \%$ of the total data). Inter-coder reliability Cohen's kappa was calculated and the results were satisfactory: .99 for whether the message was identified as a pedagogical question, and .86 for the three types of pedagogical questions (confirm, specify, and explain).

\section{Focus educators' qualifications.}

Previous studies have found that infant program quality and educator-infant interaction quality is related to the presence or absence of a university-qualified educator (Burchinal, Cryer, Clifford, \& Howes, 2002; Hestenes, Cassidy, Hegde, \& Lower, 2007; King, Pierro, Li, Porterfield, \& Rucker, 2016). Accordingly, we used a binary category of Bachelor degree 
qualified (degree qualified: $N=8$ ) or Diploma/Certificate qualified (non-degree qualified: $N$ $=19$ ) in our analysis.

\section{Data Analysis}

To answer the first research question, repeated ANOVAs were conducted to examine the extent to which the educators used the three types of pedagogical questions overall and in the two activity type when interacting with infants. To answer the second research question, a $2 \mathrm{x}$ 2 mixed factorial MANOVA was conducted using activity type (i.e., book-focused interaction vs. educator-mediated play) as a within-subject independent variable, qualification (i.e., degree qualified vs. non-degree qualified) as a between-subject independent variable, and proportions of proportions of different types of pedagogical questions (Hasan, 1989, 1991)

When quantitative differences between qualification levels were detected, a post-hoc qualitative analysis of the educators' questioning within the context of surrounded interaction was conducted in order to gain a clearer insight into the implications of questioning for the language opportunities afforded to infants. We used an inductive analysis approach (Silverman, 2006) which comprised reading each transcript while viewing the video of the interaction and making descriptive notes about the qualitative features of the interactions containing educators' questions in that particular activity context. Drawing on previous analyses of question types (Girolametto et al., 2000; Hasan, 1989, 1991; O’Brien \& Bi, 1995), notes were made about the apparent function of the educators' question within the context of the interaction. This was not only determined by the semantic choices represented by the question itself, but also by the way in which the question appeared to provoke, or to encourage a communicative response from the infant. We also considered the semantic properties of the educators' other infant-directed messages that were contained within that 
interaction. We then compared and contrasted the notes of the different qualification cohorts in order to identify similarities and differences in patterns of questioning style associated with different levels of qualification in that context. The qualitative analysis was conducted primarily by the first author, and the credibility of the analysis was determined collaboratively with the other authors who have a specialisation in educational linguistics. Extracts of transcripts were jointly considered and interpreted until a consensus about the similarities and differences between qualification cohorts was reached.

\section{Results}

\section{How frequently do educators use confirm, specify and explain pedagogical questions overall and in different activity contexts when interacting with infants?}

Table 1 presents the descriptive statistics for educators' total use of pedagogical questions as well as the three pedagogical question types overall and in the two activity contexts.

\section{Insert Table 1 around here}

Overall, pedagogical questions comprised, on average just over $16 \%$ of educators' infantdirected messages. Educators averaged $7.60 \%$ of all infant-directed messages for confirm questions, and $8.32 \%$ for specify questions. Explain questions were rare $(M=0.08 \%$ of all infant-directed messages; $M=0.57 \%$ of total pedagogical questions), with 23 of the focus educators never using explain questions in book-focused interaction and 25 never using them in educator-mediated play.

Due to the rare use of explain questions, they were excluded from the subsequent analyses. A repeated ANOVA comparing the overall proportions of confirm and specify questions was not significant: $F(1,26)=0.39, p=.54$, partial $\eta^{2}=.02$. However, we found that in the bookfocused interaction, the educators used a significantly lower proportion of confirm questions $(M=6.63 \%, S D=4.11 \%)$ than specify questions $(M=10.19 \%, S D=5.91 \%), F(1$, 
26) $=6.86, p<.05$, partial $\eta^{2}=.21$. In contrast, the educators adopted a significantly higher proportion of the confirm questions $(M=8.92 \%, S D=5.02 \%)$ than specify questions $(M=$ $6.10 \%, S D=4.01 \%)$ in the educator-mediated play, $F(1,26)=5.35, p<.05$, partial $\eta^{2}=.17$.

\section{To What Extent Do Activity Contexts and Educators' Qualification Levels Explain}

\section{Variations in Educators' Pedagogical Questions?}

Table 2 displays the proportions of confirm and specify pedagogical questions produced by the differently qualified educators in the two different activity contexts, as well as the results of mixed MANOVA.

\section{Insert Table 2 around here}

For confirm questions, the results of the mixed MANOVA revealed a significant main within-subject effect for activity context, $F(1,25)=18.34, p<.01$, partial $\eta^{2}=.42$. Overall, educators used significantly higher proportions of confirm questions during the educatormediated play $(M=8.92 \%, S D=5.02 \%)$ than during the book-focused interaction $(M=$ $6.63 \%, S D=4.11 \%)$.

There was also a significant main between-subject effect for educator qualification, $F(1,25)$ $=6.02, p<.05$, partial $\eta^{2}=.19$, revealing that irrespective of the activity context, degree qualified educators $(M=9.57 \%, S D=3.13 \%)$ used significantly higher proportions of confirm questions than non-degree qualified peers $(M=6.78 \% S D=3.49 \%)$. A significant interaction effect between activity contexts and qualification was also observed, $F(1,25)=$ $18.80, p<.001$, partial $\eta^{2}=.43$, demonstrating that while the non-degree qualified educators produced a similar proportion of confirm questions during the book-focused interaction $(M=$ $6.77 \%, S D=4.55 \%)$ and educator-mediated play $(M=6.73 \%, S D=3.35 \%)$, the degree 
qualified educators' use of confirm questions varied according to the activity context. Specifically, degree qualified educators used a higher proportion of confirm questions during educator-mediated play $(M=14.14 \%, S D=4.71 \%)$ than during the book-focused interaction $(M=6.29 \%, S D=3.05 \%)$. The interaction effect is visually displayed in Figure 1 .

\section{Insert Figure 1 around here}

For specify questions, the effect of activity context was also significant, $F(1,25)=6.00, p<$ .05 , partial $\eta^{2}=.19$. Educators used a significantly higher proportion of specify questions during the book-focused interaction $(M=10.19 \%, S D=5.91 \%)$ than during the educatormediated play $(M=6.10 \%, S D=4.01 \%)$.

The main effect of qualification on educators' use of specify questions was not significant, $F$ $(1,25)=1.16, p=.29$, partial $\eta^{2}=.04$. However, an interaction effect between activity and qualification approached significance, $F(1,25)=3.97, p=.057$, partial $\eta^{2}=.14$. Figure 2 illustrates how the degree qualified educators used similar proportions of specify questions across the two activity contexts (book: $M=7.17 \%, S D=1.91 \%$, play: $M=6.60 \%, S D=4.62 \%$ ), while the non-degree qualified educators used higher proportions of specify questions during their book-focused interaction $(M=11.46 \%, S D=6.58 \%)$ than during play $(M=5.89 \%, S D=$ $3.84 \%)$.

\section{Insert Figure 2 around here}

\section{Post hoc Qualitative Analysis}

Our quantitative analysis thus revealed that degree and non-degree qualified educators differed in their patterns of confirm and specify question use across the two activity contexts. 
To better understand the implications of these quantitative differences findings for infants' language opportunities, we conducted a post-hoc descriptive analysis of educators' use of questioning within the context of the surrounding interaction in the activity context associated with the quantitative difference.

Following the significant quantitative interaction effect for confirm questions, we conducted the post-hoc qualitative analysis in the context of mediated play. We found that, overall, the educators' confirm questions inquired about infants' intentions (e.g., Are you going to dig a hole? or Are you going to make another cat?) or experiential world (e.g., Can you see through there?; Do you think the bigger one will fit? and Has it made a pattern?). Confirm questions appeared effective as a conversational device that could be used to 'tune into' these infants' experiences and to encourage ongoing interactions around these shared experiences. The difference between differently qualified educators therefore was related predominantly to how frequently confirm questions were used. Our qualitative comparison revealed that the transcripts of many non-degree qualified educators included long episodes of statements or directives which contained no or very few confirm questions. A typical example is provided in extract 1 below, which sees only one confirm question used among a number of behavioural directives:

\section{Extract 1}

Educator (E14) is sitting on the floor surrounded by various toys. As a toddler moves into the space, the educator holds out the ball and asks:

Educator: Want to play catch? (she tosses the ball to the toddler)

Educator: Catch.

Educator: Catch.

Another infant throws a ball to the educator, who catches it and responds:

Educator: Big roll.

Educator: Good throw. 
The older toddler returns and waves a small blanket that he is carrying towards the educator. The educator and toddler both laugh:

Educator: Be gentle.

Educator: Ahh!

Educator: Be gentle.

In contrast, all but one of the degree-qualified educator transcripts were regularly punctuated by confirm questions. Extract 2 below illustrates the typical way in which degree-qualified educators used a number of confirm questions in succession, and the way in which this created opportunities for infants' participation in reciprocal interactions.

\section{Extract 2}

Educator (E60) is sitting at the playdough table with a small group of infants.

One infant points to a small egg-timer placed at the other side of the table:

Infant: Alarm, alarm.

Educator: The alarm.

Educator: Do we need to set the alarm?

Infant: Yeah. (Educator reaches and turns the dial)

Educator: Let's try and see if it's working okay?

Infant: Yeah

Educator: It might not be working. (Educator holds the timer to her ear)

Educator: Can you hear it ticking? (She holds the timer out to the infant's ear)

Educator: Tick, tick, tick, tick, tick

Following the detected context $\mathrm{x}$ qualification interaction effect for specify question, we then examined the use of specify questions by differently qualified educators in the book-focused interactions. This revealed that non-degree qualified educators tended to include interactions in which specify questions were used in succession to elicit known answers from the infant. 
Extract 3 provides a typical example, during which the educator can be seen to use specify questions in an apparent effort to prompt verbal labelling.

\section{Extract 3}

Educator (E26) is sitting on a low chair surrounded by a group of infants, three of which are listening to her reading a story about a mouse creeping in a house. She turns a page and holds it up for the infants to see.

Educator: What can we see on this page here?

The educator points to the picture

Educator: What's on this page?

Educator: Biscuits.

Educator: (turning the page) What's on this one?

The educator is distracted momentarily by a toddler who is crawling over another child

Educator: Tina! That's going to hurt Jack.

She helps the crawling infant to sit and points again to the page

Educator: What can you see over here Tina?

Educator: What's that?

Tina: Melon.

Educator: Melon, watermelon.

Educator: What's on this page?

Jack: Pumpkin.

Educator: And this one?

Jack: Cheese.

In contrast, degree qualified educators expressed fewer specify questions, but tended to follow specify questions with extensions, thus adding more information to the topic of interaction. In Extract 4, for example, this educator uses a specify question to initiate an interaction topic in which she then goes on to elaborate. 


\section{Extract 4}

Educator (E30) is sitting on the floor with two infants sitting by her side. They have chosen a book to read about making lemonade. The educator turns the first page to see a picture of a glass of liquid.

Educator: $\underline{\text { Oh, what's that? }}$

Infant: Ah ... Jooo

Educator: It does look like juice.

Educator: It's a special juice called lemonade.

The educator turns the page and reads the book script. After completing the script, she points to the character and comments:

Educator: The lemonade has all gone

Educator: Uh oh.

Infant 1 and 2: Uh oh.

Educator: He's still thirsty.

Educator: What is he going to drink?

Infant: Water

Educator: Water.

Educator: Just like what we did with the cake.

\section{Discussion}

This study explored the frequency and characteristics of educators' infant-addressed questions in infant long day care rooms. By using Hasan's $(1989,1991)$ semantic network as an analytical framework, we analysed the semantic content of the educators' pedagogical questioning in terms of the nature of the response sought from the infant, rather than simply by focusing either on grammatical form or on speech function. We were specifically interested in the prevalence of different types of pedagogical questioning and whether variation was associated with the immediate activity context and the associations between levels of educators' early childhood qualifications. 


\section{Frequency of Educators' Use of Pedagogical Questions.}

While the value of 'open-ended' explain questions is often extolled in research and practice with older children (Chappell et al., 2008; Siraj-Blatchford \& Manni, 2008), our findings question whether they should be similarly privileged with infants. We found that explain questions were used rarely by the participating educators, which, given that explain questions often seek extended verbal responses, is not surprising given the pre- and emerging verbal abilities of this age group. Our finding confirms previous results about the infrequent use of explanation-seeking questioning with very young children (Cicognani \& Zani, 1992; Davis \& Torr, 2015) and suggests that educators' questioning style is adapted to suit the language capabilities of the children with whom they work.

Nearly half of the pedagogical questions posed by educators in this study were confirm questions; that is, the educator provided the representational content in her question and the infant was positioned as one who could potentially confirm or deny. In studies with older, more linguistically competent preschoolers, such questions are often referred to as 'closed', as they are unlikely to stimulate extended exchanges or further exploration of a topic (Allerton, 1993; Siraj-Blatchford \& Manni, 2008). However, Hasan (1989) suggests that a significant function of confirm questions is to enable the questioner to seek and confirm another's intentions, perceptions and understandings. Our qualitative analysis supports her view, with educators using confirm questions to request feedback about these infants' experiences, thus positioning infants as an interactive partner who can respond verbally or non-verbally to the interpretation. Educators' use of specify questions comprised the other main portion of the total pedagogical questions. One of the key linguistic achievements of infants in the second year of life is the development of naming. While specify questions may also be regarded as relatively 'closed' in nature, it appears that they provide opportunities for infants to use their developing communication skills to name the phenomena in their 
environment, thus representing their existing understanding. Our findings suggest that these two question types elicit verbal and non-verbal communicative responses from infants, and therefore should not be considered as 'closed' in the way that they are with older children.

\section{Explaining the Variation in Educators' Use of Pedagogical Questioning}

More detailed information about educators' use of confirm and specify questions was derived when we analysed the effects of activity context and qualification levels. Consistent with previous research (Girolametto \& Weitzman, 2002; Girolametto et al., 2000; O’Brien \& Bi, 1995), we found that different activity contexts were associated with different patterns of educator questioning, and therefore different language opportunities for these infants. These findings add to recent work with infants as well as preschool children that highlights the need to consider closely activity contexts when analysing the language opportunities that are available to young children (e.g., Degotardi et al., 2016; Dickenson, Hofer, Barnes, \& Grifenhagen, 2014; Soderstrom \& Wittebolle, 2013).

Moreover, we found that certain activity contexts appeared to prompt differently-qualified educators to modify the frequency of their question use. These findings add detail and complexity to previous studies which have demonstrated an effect of qualification on broad measures of infant program quality or infant-educator sensitivity and stimulation (Degotardi, 2010; Goelman et al., 2006; Manlove et al., 2008; National Institute of Child Health and Human Development Early Child Care Research Network, 2002). Our study found that educators' qualification levels were associated with different patterns of question use, leading to different learning opportunities for infants, and that these opportunities presented in specific activity contexts. During mediated play, higher qualified educators' frequent use of confirm questions, when compared to lower qualified educators, may reflect a sensitivity to infants' experience that has previously been associated with more highly qualified educators 
(Degotardi \& Sweller, 2012; Frampton, Michal, \& Jenkins, 2009; Manlove et al., 2008), and such sensitivity may ultimately create a language environment which foregrounds interactive potential.

During book reading, the quantitative and qualitative variation in these educators' use of specify questions created quite different learning opportunities. Non-degree qualified educators tended to use specify questions to encourage infants to name entities in books. While this provides infants with opportunities to represent their knowledge in verbal or nonverbal language forms, it may be less effective in promoting infant participation in the interaction (Girolametto et al., 2000). Degree qualified educators took a different approach, whereby requests to label were followed by topic extensions, which are regarded as a key language-supporting strategy (Bloom, Margulis, Tinker, \& Fujita, 1996; Girolametto \& Weitzman, 2002). In these instances, topic extensions functioned to introduce novel, diverse vocabulary and inject new information. Our findings again suggest important points of difference in the interaction style of differentially qualified educators, and suggest that higher-qualified educators are better equipped to use questioning as a means of stimulating conversational exchanges as well as enriching the learning potential of the interaction.

\section{Limitations and Directions for Future Research}

This study was based on the language used by 27 focus educators chosen out of an initial data base of 56 educators on the basis that, during their 180 minutes of video-recorded data, they participated in a minimum of 10 minutes of book-focused interactions and educator-mediated play. The resulting sample was relatively small, and our results should therefore be interpreted as exploratory. Future research with larger sample sizes are needed to confirm our findings. Our sample size also raises another significant issue that requires further investigation. Of our initial participants, only 31 engaged in book-focused interactions during 
the entire observation time. Given the central role played by shared reading in children's language and literacy development, this indirect and unanticipated finding is disturbing. Further research is needed to determine the reasons for the lack of book-focused interaction in long day care, and the characteristics of those educators who do provide rich, book-related interactions with infants.

A further limitation of this study is that this study focused on educator questions only, without consideration of the infants' responses to educator questions. We found that questions were often used as a means of tuning in to infants' intentions, to encourage naming and, in some instances, as a catalyst for extended conversations. As previous research has determined relationships between educators' language-supporting strategies and infant language use, future research needs to focus on infants' responses to educators' questions, in order to gain a fuller understanding of the nature and influence of questioning as a pedagogical strategy for teaching and learning.

Finally, when the focus of questioning extends to its role in learning as well as language development, future research is needed to determine whether infants themselves engage in questioning behaviour. There is limited research available in home contexts to suggest that questioning does start to emerge before the age of two years (Chouinard, 2007), but as yet, no known research has examined this phenomena in ECEC contexts. How, and in what contexts infants use questioning as a means of information exchange is therefore a question for future studies to explore.

\section{Conclusion}

This study contributes to a body of evidence to show that both the context of interaction and the qualifications of infant educators are significant features of the language-learning environment provided for infants in ECEC centres. Educators' use of pedagogical 
questioning has the potential to position infants as conversational partners long before they can use language to converse fluently, but our findings suggest that how this is realised is contingent on the educational activity taking place and the knowledge and skill base of the educator. When used effectively, infant-addressed questions foreground the infant as a "thinker" and "knower" and consequently create, through the educator's language, an educational environment which tacitly acknowledges the principle that each person has an individual mind and point of view which can only be accessed by others through verbal interaction.

Acknowledgement: We gratefully acknowledge and thank the educators and infants who participated in this study, and appreciate the fine work of the Research Assistants who made the study possible. 


\section{References}

Allerton, M. (1993). “Am I asking the right questions?” What teachers ask of children. International Journal of Early Childhood, 25, 42-48. doi:10.1007/BF03174630

Bateman, A. (2013). Responding to children's answers: Questions embedded in the social context of early childhood education. Early Years: An International Research Journal, 33(3), 275-288. doi:10.1080/09575146.2013.800844

Bloom, L., Margulis, C., Tinker, E., \& Fujita, N. (1996). Early conversations and word learning: Contributions from child and adult. Child Development, 67, 3154-3175.

Burchinal, M. R., Cryer, D., Clifford, R., \& Howes, C. (2002). Caregiver training and classroom quality in child care centres. Applied Developmental Science, 6(1), 2-11. doi:10.1207/S1532480XADS0601_01

Bus, A. G., van IJzendoorn, M. H., \& Pellegrini, A. D. (1995). Joint Book Reading Makes for Success in Learning to Read: A Meta-Analysis on Intergenerational Transmission of Literacy. Review of Educational Research, 65(1), 1-21. doi:10.3102/00346543065001001

Cabell, S. Q., Justice, L. M., McGinty, A. S., DeCoster, J., \& Forson, L. D. (2015). Teacherchild conversations in preschool classrooms: Contributions to children's vocabulary development. Early Childhood Research Quarterly, 30, 80-92. doi:10.1016/j.ecresq.2014.09.004

Chappell, K., Craft, A., Burnard, P., \& Cremin, T. (2008). Question-posing and questionresponding: The heart of 'possibility thinking' in the early years. Early Years: An International Research Journal, 28(3), 267-286. doi:10.1080/09575140802224477

Chouinard, M. M. (2007). Children's Questions: A mechanism for cognitive development. Monographs of the Society for Research in Child Development, 72(1).

Cicognani, E., \& Zani, B. (1992). Teacher-children interactions in a nursery school: An exploratory study Language and Education, 6(1), 1-12. doi:10.1080/09500789209541321

Davis, B., \& Torr, J. (2015). Educators' use of questioning as a pedagogical strategy in long day care nurseries. Early Years: An International Research Journal, 36(1), 97-111. doi:10.1080/09575146.2015.1087974

Degotardi, S. (2010). High-quality interactions with infants: Relationships with early childhood practitioners' interpretations and qualification levels in play and routine contexts. International Journal of Early years Education, 18(1), 27-41. doi:10.1080/09669761003661253

Degotardi, S., \& Sweller, N. (2012). Mind-mindedness in infant child-care: Associations with early childhood practitioner sensitivity and stimulation. Early Childhood Research Quarterly, 27, 253-265.

Degotardi, S., Torr, J., \& Nguyen, N. (2016). Infant-toddler educators' language support practices during the context of mealtime. Australasian Journal of Early Childhood Education, 41(1).

Dickenson, D., K, Hofer, K. G., Barnes, E. M., \& Grifenhagen, J. F. (2014). Examining teachers' language in Head Start classrooms from a systemic linguistics approach. Early Childhood Research Quarterly, 29, 231-244. doi:10.1016/j.ecresq.2014.02.006

Durden, T., \& Dangel, J. R. (2008). Teacher-involved conversations with young children during small group activity. Early Years: Journal of International Research and Development, 28(3), 251-266. doi:10.1080/09575140802393793

Fletcher, K. L., \& Reese, E. (2005). Picture book reading with young children: A conceptual framework. Developmental Review, 25, 64-103. doi:10.1016/j.dr.2004.08.009 
Frampton, K. L., Michal, P., \& Jenkins, J. M. (2009). Caregivers' use of metacognitive language in child care centres: Prevalence and predictors. Early Childhood Research Quarterly, 24(3), 248-262. doi:10.1016/j.ecresq.2009.04.004

Gilkerson, J., Richards, J. A., \& Topping, K. J. (2015). The impact of book reading in the early years on parent-child language interaction. Journal of Early Childhood Literacy, 17(1), 92-110. doi:10.1177/1468798415608907

Girolametto, L., \& Weitzman, E. (2002). Responsiveness of child care providers in interactions with toddlers and preschoolers. Language Speech and Hearing Services in Schools, 33, 268-281.

Girolametto, L., Weitzman, E., van Lieshout, R., \& Dawna, D. (2000). Directiveness in teachers' language input to toddlers and preschoolers in day care. Journal of Speech, Language and Hearing Research, 43, 1101-1114.

Goelman, H., Forer, B., Kershaw, P., Doherty, G., Lero, D., \& LaGrange, A. (2006). Towards a predictive model of quality in Canadian child care centres. Early Childhood Research Quarterly, 21, 280-295. doi:10.1016/j.ecresq.2006.07.005

Halliday, M. A. K. (1994). An introduction to functional grammar (2nd Ed.). London Arnold.

Hasan, R. (1989). Semantic variation and sociolinguistics. Australian Journal of Linguistics, 9(2), 221-275. doi:10.1080/07268608908599422

Hasan, R. (1991). Questions as a mode of learning in everyday talk. In T. Le \& M. McCausland (Eds.), Language education: Interaction and development. Proceedings of the International Conference, Vietnam (pp. 70-119). Launceston: University of Tasmania Press

Hasan, R. (1996). Semantic networks: A tool for the analysis of meaning. In C. Cloran, D. Butt, \& G. Williams (Eds.), Ways of saying, ways of meaning. Selected papers of Ruqaiya Hasan (pp. 104-131). London: Cassell.

Hestenes, L. L., Cassidy, D. J., Hegde, A. V., \& Lower, J. K. (2007). Quality in inclusive and noninclusive infant and toddler classrooms. Journal of Research in Childhood Education, 22(1), 69-84. doi:10.1080/02568540709594613

Hoff, E. (2006). How social contexts support and shape language development. Developmental Review, 26, 55-88. doi:10.1016/j.dr.2005.11.002

Hu, J., Torr, J., Degotardi, S., \& Han, F. (2017). Educators' use of commanding language to direct infants' behaviour: relationship to educators' qualifications and implications for language learning opportunities. Early Years, 1-15. doi:10.1080/09575146.2017.1368008

Justice, L. M., Jiang, H., \& Strasser, K. (2018). Linguistic environment of preschool classrooms: What dimensions support children's language growth. Early Childhood Research Quarterly, 42, 79-92. doi:http://dx.doi.org/10.1016/j.ecresq.2017.09.003

King, E. K., Pierro, R. C., Li, J., Porterfield, M. L., \& Rucker, L. (2016). Classroom quality in infant and toddler classrooms: impact of age and programme type. Early Child Development and Care, 25, 875-893. doi:10.1080/03004430.2015.1134521

Manlove, E. E., Vazquez, A., \& Vernon-Feagans, L. (2008). The quality of caregiving in chld care: Relations to teacher complexity of thinking and perceived supportiveness of the work environment. Infant and Child Development, 17, 203-222. doi:10.1002/icd.547

Massey, S., Pence, K. L., Justice, L. M., \& Bowles, R. P. (2008). Educators' use of cognitively challenging questions in economically disadvantaged preschool classroom contexts. Early Education and Development, 19(2), 340-360. doi:dx.doi.org/10.1080/10409280801964119. 
McGee, L. M., \& Richgels, D. J. (2003). Designing early literacy programs: Strategies for at-risk preschool and kindergarten children. . New York The Guilford Press. .

National Institute of Child Health and Human Development Early Child Care Research Network. (2002). Child-care structure - process - outcome: Direct and indirect effects of child-care quality on young children's development. Psychological Science, 13(3), 199-206. doi:10.1111/1467-9280.00438

O’Brien, M., \& Bi, X. (1995). Language learning in context: Teacher and toddler speech in three classroom play areas. . Topics in Early Childhood Special Education, 15, 148163. doi:10.1177/027112149501500202

Silverman, D. (2006). Interpreting qualitative data. London: Sage.

Siraj-Blatchford, I., \& Manni, L. (2008). 'Would you like to tidy up now?' An analysis of adult questioning in the English Foundation Stage. Journal of International Research and Development, 28(1), 5-22. doi:10.1080/09575140701842213

Snow, C. E., \& Uccelli, P. (2009). The challenge of academic language. In D. Olson \& N. Torrance (Eds.), The Cambridge Handbook of Literacy, (pp. 112-133). Cambridge, UK: Cambridge University Press. .

Soderstrom, M., \& Wittebolle, K. (2013). When do caregivers talk? The influence of activity and time of day on caregiver speeach and child vocalizations in two childcare environments. PLOS ONE, 8(11). Retrieved from doi:10.1371/journal.pone.0080646

Wittmer, D. S., \& Honig, S. (1991). Convergent or divergent? Teacher questions to three year old children in day care Early Child Development and Care, 68, 141-147. doi:10.1080/0300443910680113

Zauch, L. H., Thul, T. A., Mahoney, A. E. D., \& Stapel-Wax, J. L. (2016). Influence of language nutrition on children's language and cognitie development: An integrated review. Early Childhood Research Quarterly, 36, 318-333.

doi:10.1016/j.ecresq.2016.01.015 